\title{
COVID-19 Entwined the Dynamic Relationship between Stock Returns and Macroeconomic Variables
}

\author{
Amina Malik, Babar Zaheer Butt, Haroon Aziz \\ COMSATS University Islamabad, Wah Campus, Pakistan \\ Post Doctorate Research Fellow, Tohoku University of Community Service \& Science, Japan \\ All Pakistan Textile Mills (APTMA), Pakistan \\ amina_malik_2000@yahoo.com, babarzb@gmail.com,haroonpvma@gmail.com
}

\begin{abstract}
The state of any stock market is dependent on the economic and financial conditions prevailing in the country and can be used to see the mirror image of collective disposition in financial and economic terms. Therefore, this study examines the dynamic relationship between macroeconomic variables and stock prices in Pakistan in the COVID-19 pandemic scenario. For this purpose, monthly data has been taken from Jan 2019 to June 2021 and divided into Pre-COVID, COVID and overall periods. Data related to economic variables and stock prices have been retrieved from various sources including Statistical Reviews \& Bulletins of State Bank of Pakistan, Karachi Stock Exchange and Pakistan Economic Survey. To assess the relationship between economic variables and stock prices, Cointegration, Granger-causality and Impulse Repose Function Tests have been applied on three data series. The results of the study reveal that there is a long-term equilibrium relationship between all economic variables and stock prices in the Pre-COVID period. However, most of the economic variables do not have such a relationship during the COVID period and the pattern of the relationship is almost the same in the overall period. Even the short-run dynamic relationship between economic variables and stock returns is affected by the pandemic. The results show that economic variables affect stock returns differently in the COVID situation than in the Pre-COVID scenario and it also affects the short-run relationship in the overall period. This research study provides imminent findings on the linkage between macroeconomic variables and stock prices in the Pakistani context. It helps investors and regulators in customizing their decisions and macroeconomic regulations respectively to improve the financial and economic stability of the country in the wake of the pandemic. Keeping in view the findings and implications of this study, investors and stakeholders need to weigh the uncertainty associated with COVID-pandemic before making investment decisions.
\end{abstract}

Keywords: Macroeconomic Variables, Karachi Stock Exchange, Granger Causality, Pakistan.

\section{Introduction}

COVID-19 initially reported in Dec 2020 in Wuhan, China. It surged chaos and economic uncertainty across the globe with its impact on every sphere including businesses, economies and individuals (Baker, Bloom, Davis, \& Terry, 2020). The severity of the pandemic was equally stern as of the great depression; as it affected the global stock markets naming a few including Europe, Australia, America and Asia. The great depression was endogenous in nature due to the bad decisions of stakeholders. Whereas, COVID-19 is exogenous in nature as it has affected the real economies and stock indexes (Li, Su, Altuntaş, \& Li, 2021).

Stock market returns are susceptible to announcements and uncertainties (Hillier \& Loncan, 2019). Moreover, stock markets also reacted to earlier outbreaks of contagious diseases including SARS, Ebola and MERS (Ichev \& Marinč, 2018). Keeping in view these factors and news effects, stock markets are indicators of the financial health of stock markets (Younis, Longsheng, Basheer, \& Joyo, 2020). Above all, financial and macroeconomic indicators also influence the stock market returns. Industrial production index and interest rates contribute to almost fifty percent of annual movements in stock prices (Peiro, 2016). Moreover, stock market returns are also affected by pandemic (Engelhardt, Krause, Neukirchen, \& Posch, 2020).

In order to handle the adversities of the pandemic and its impact on the economy, countries have taken various measures including social distancing, lockdowns as well as vaccination drive(Kartal, Ertuğrul, \& Ulussever, 2021). Due to the uncertainty in the business arena and lack of clear visibility, the choices of investment decisions are extremely dicey. In order to mitigate these challenges, policy interventions in the shape of conducive policies as well as enabling a business environment are highly required. 
The Pakistani Stock Market has been considered among the best performing exchanges in the world as it has undergone an intense transformation. To facilitate all stakeholders including investors, the government had taken a number of initiatives including liberal policies which have instigated foreign investment in the country and flourished the Pakistani stock market in the recent past. Further, it has become quite an attractive investment opportunity for local and international investors. However, COVID has affected world stock markets. Now, it has also become imperative to study whether COVID Pandemic has affected the performance of the Pakistani stock market.

This research study significantly adds to the existing literature by examining whether the macroeconomic variables affect stock prices in Pakistan in the wake of the worldwide COVID-19 pandemic. This study particularly focuses on Consumer Price Index (CPI), Karachi Interbank Offered Rate (KIBOR), Bank Spread (BS), Industrial Production Index (IPI), Exchange Rate (ExR), Money Supply (MS), Foreign Direct Investment (FDI) and Stock Value of KSE 100 Index in Pakistan with a concentration on Pre and COVID pandemic period. Earlier studies have examined the association among macroeconomic variables and stock exchanges in developed countries (Bhuiyan \& Chowdhury, 2020), symmetrical cointegrating relationship between economic variables and KSE index in the wake of global financial crises (Sheikh, Asad, Israr, Tabash, \& Ahmed, 2020). Whereas, the focus of this study is particularly on Pakistan due to the unpredictable characteristics of the Karachi stock exchange (Sheikh et al., 2020). This study provides imminent findings for investors, regulators and researchers on the linkage among macroeconomic variables and Stock Prices in the Pakistani context and shall offer useful information to amplify their returns in the presence of an ongoing pandemic situation.

The research paper is organized as follows. Section 2 describes the literature review, theoretical postulates and hypotheses development. Section 3 presents the research design which includes sample period and data selection, estimation strategy and method. Empirical results are discussed in section 4. Section 5 concludes the study.

\section{Literature Review, Theoretical Postulates and Hypotheses Development}

\section{Arbitrage Pricing Theory}

This research study is anchored based on Arbitrage Pricing Theory (APT) to explain the relationship between macroeconomic variables and stock returns. APT was postulated by Ross (Ross, 1976) and it was improved as compared to Capital Asset Pricing Model(CAPM), which was hypothesized by Sharpe (Markowitz, 1968). CAPM is loved for its simplicity and criticized due to its unrealistic application. APT assumes that return is not only dependent on current and future market risk but also other macroeconomic factors. Suffice to say that APT return on assets is dependent on economic features whereas, in CAPM, market risk is the underlying factor affecting the returns(Dada, Mokuolu, Alabi, \& Miracle, 2021).

\section{Empirical Literature on Macroeconomic Variables and Stock Returns}

Many empirical research studies have validated the relationship between macroeconomic variables and stock returns in the context of developed and developing countries. Most of the studies posit that there is a longterm association between macroeconomic variables and stock returns. The recent study on macroeconomic variables and stock markets in the US and Canada context from 2000 to 2018 revealed that there is a longterm association among money supply, industrial production, long-term interest rate and sectoral indices (Bhuiyan \& Chowdhury, 2020).

\section{Consumer Price Index (CPI) and Stock Returns}

Inflation is termed as an increase in the prices of the goods and services that are purchased by households. We have used the Consumer Price Index (CPI) as an indicator of inflation in this study. The study on the impact of macroeconomic variables as well as financial indicators on the stock index has found that the Thai stock market index has a long-run association with the Consumer Price Index, exchange rate and broad money supply(Chaengkham \& Wianwiwat, 2021). Moreover, the study on the impact of macroeconomic variables on the stock market in the United Kingdom, also showed that inflation Granger causes the stock market return of the UK (Neifar et al., 2021). Likewise, inflation Granger causes the return of Swedish stock market index OMXS30 study on macroeconomic variables (Cengiz \& Holmer, 2021). 


\section{Interest Rate, Bank Spread, Industrial Production and Stock Returns}

The economic growth of a country is dependent on the stock index as well as on interest rate, which has ultimate implications on monetary and government policies, financial instruments in the financial markets and institutions (Alam \& Uddin, 2009). Further, the Industrial production index and interest rates contribute to almost fifty percent of annual movements in stock prices (Peiro, 2016). Therefore, Karachi Interbank Offer Rate (KIBOR) has been taken as an independent variable in this study as a proxy of interest rate. It has been preferred over other indicators of efficiency due to its usage as the policy indicator, simplicity and availability of the data. The study on the impact of macroeconomic variables on the Swedish stock market index OMXS30 showed a bidirectional relationship between interest rate and the return of OMXS30 (Cengiz \& Holmer, 2021). Therefore, we also expect a causal relationship between interest rate and stock return as the high interbank rate triggers investors by switching investments from banks to the stock market, which gives rise to business and ultimately results in better stock returns.

Changes in the bank spread affect the economy as well as stock markets as the borrowing becomes expensive for the individuals as well as for the business person. The investments in stock surge due to a reduction in interest rate, whereas the rise in interest rate negatively affects stocks (Torbira \& Agbam, 2017). A study conducted on the impact of macroeconomic factors on stock return in the Nigerian stock market from 1998 to 2019 has found that industrial production has a positive and significant impact on stock return (Pole \& Cavusoglu, 2021). Moreover, another research regarding the linkage between macroeconomic factors and the stock market in Pakistan from 2011 to 2017, also revealed that industrial production positively affects the fluctuations of stock market returns (Aziz, Marwat, \& Mustafa, 2021).

\section{Exchange Rate and Stock Returns}

The stock market and exchange rate have a significant role in global businesses and financial markets. A recent study on the impact of macroeconomic variables and financial indicators on the stock index has found that the Thai stock market index has a long-run relationship with the exchange rate(Chaengkham \& Wianwiwat, 2021). Moreover, the study conducted on the impact of macroeconomic factors on stock return in the Nigerian stock market from 1998 to 2019 has found that the exchange rate has a negative impact on stock return (Pole \& Cavusoglu, 2021). Whereas, another study on the causal relationship between Pakistan stock exchange market and exchange rate from January 2015 to December 2019, findings reveal that there is a positive relationship between exchange rate and stock price and they are dependent on each other (Amarkhil, Hussain, \& Ayoubi, 2021).

\section{Money Supply, FDI and Stock Return}

Monetary policy also affects stock returns, as the expansionary policy shore up the growth and development, whereas tightened policy has a negative impact. Further, most of the countries also used monetary policy tools to handle the pandemic situation (Kartal et al., 2021). Moreover, a study on the association between macroeconomic variables and the stock market showed that money supply has a direct relationship with the stock prices in the Lithuanian market (Pilinkus \& Boguslauskas, 2009). Further, a recent study on the impact of macroeconomic variables and financial indicators on the stock index has found that the Thai stock market index has a long-run relationship with the broad money supply (Chaengkham \& Wianwiwat, 2021). Stock markets are also affected due to flows of foreign portfolios, especially in a pandemic situation. All countries are affected due to pandemic but the developing and emerging countries are more affected due to their dependence on FDI (Kartal et al., 2021).

\section{Empirical Literature on Macroeconomic Variables and Stock Returns in COVID}

The findings of the recent study on the impact of the COVID-19 pandemic on emerging stock markets have revealed that pandemic impact has gradually decreased and started to taper off by mid-April 2020 (Topcu \& Gulal, 2020). World stock markets have shown different degrees of volatility in the COVID-19 pandemic situation. The study has been conducted by using data of thirty developed and emerging markets and the results reveal that country economic factors, characteristics and policies like monetary policy, financial development, corporate governance, economic resilience and sound health system can play a positive role and mitigate the negative impacts of the pandemic on stock market returns (Uddin, Chowdhury, Anderson, \& Chaudhuri, 2021). 


\section{Research Design and Sample Selection}

\section{Variable Selection and Data Period}

This research study has incorporated Consumer Price Index (CPI), Karachi Interbank Offer Rate (IR), Bank Spread (BS), Industrial Production Index (IPI), Exchange Rate (ExR), Money Supply (MS) and Foreign Direct Investment (FDI) to determine the association between macroeconomic variability and stock returns in Pakistan in Pre-COVID, COVID and overall period, by utilizing the times series monthly data from January 2019 to June 2021. The data has been collected from various sources including Statistical Reviews \& Bulletins of State Bank of Pakistan, Karachi Stock Exchange and Pakistan Economic Survey issued by Finance Division of Government of Pakistan.

The sample period has been classified into Pre-COVID, COVID and overall period that enables to determine whether the impact of macroeconomic variables on stock prices remains the same during different types of scenarios. If the pandemic has affected the relationship during OVID, in contrast to the pre-COVID regime then consideration of this particular time frame is more significant and implies that pandemic has affected the set pattern of relationship between macroeconomic variables and stock exchange returns.

\section{Estimation Methods}

To study the association of macroeconomic variables which represents the economic and financial aspects and stock returns in Pakistan in pre-COVID, COVID pandemic and overall period, the following tests have been applied:-

\section{Descriptive Statistics}

We have estimated the stochastic properties of the data series using descriptive statistics which include the mean, skewness and kurtosis.

\section{Augmented Dickey-Fuller Test-ADF}

We have examined the stationary of the data by using Augmented Dickey-Fuller Test. ADF test was applied both at the level and differenced data.

\section{Johansen Cointegration Test}

Johansen Cointegration Test has been applied to assess the long-term equilibrium relationship between nonstationary time series. VAR-based cointegration test was applied using the methodology developed in Johansen $(1991,1995)$ and Johansen \& Juselius, 1994.

$\mathrm{y}_{\mathrm{t}}=\mathrm{a}_{0}+\mathrm{a}_{1} \mathrm{y}_{\mathrm{t}-1}+\ldots \ldots \ldots \mathrm{a}_{\mathrm{p}} \mathrm{y}_{\mathrm{t}-\mathrm{p}}+\mathrm{B}_{\mathrm{xt}}+\mathrm{e}_{\mathrm{t}}$

Where yt is a k-vector of non-stationary I(1) variables, $x t$ is a $d$-vector of deterministic variables, and $e_{t}$ is a vector of innovations

\section{Granger Causality}

Granger Causality Test has been applied to determine the short-run dynamic relationship between stock returns and economic variables of this study. We have carried out a pairwise Granger causality Test.

$y_{t}=a_{0}+a_{1} y_{t-1}+\ldots \ldots \ldots a_{1} y_{t-1}+b_{1} x_{t-1}+\cdots \ldots \ldots b_{1} x_{t-1}+e_{t}$

$\mathrm{y}_{\mathrm{t}}=\mathrm{a}_{0}+\mathrm{a}_{1} \mathrm{y}_{\mathrm{t}-1}+\ldots \ldots \ldots \mathrm{a}_{1} \mathrm{y}_{\mathrm{t}-1}+\mathrm{b}_{1} \mathrm{x}_{\mathrm{t}-1}+\cdots \ldots \ldots \mathrm{b}_{1} \mathrm{x}_{\mathrm{t}-1}+\mathrm{u}_{\mathrm{t}}$

\section{Impulse Response Function}

We have estimated the Impulse response function for stock returns by using Choleski decomposition on a VAR model. It was applied to get quantitative figures regarding the impact period and its return to equilibrium. An impulse response function traces the effect of a one-time shock to one of the innovations on the current and future values of the endogenous variables.

\section{Empirical Results}

The results have been divided into sub-sections. The first section covers descriptive statistics and data normality. The second section includes the results of unit root testing. The third section is about the results of 
co-integration. The fourth section is about the results of the pairwise Granger-causality Test. The fifth section is about the results of the Impulse Response Function.

Descriptive statistics:

We have estimated the descriptive statistics of the key macroeconomic variables and stock returns in the preCOVID, COVID and overall period. Table 1 reports descriptive statistics results that include the mean, Skewness and Kurtosis of all the variables used in the study.

Table 1: Descriptive Statistics

\begin{tabular}{|c|c|c|c|c|c|c|c|c|c|}
\hline \multirow{2}{*}{$\overbrace{\frac{\pi}{\pi}}^{\frac{0}{\pi}}$} & \multicolumn{3}{|c|}{ Mean } & \multicolumn{3}{|c|}{ Skewness } & \multicolumn{3}{|c|}{ Kurtosis } \\
\hline & $\begin{array}{c}\text { Pre- } \\
\text { COVID }\end{array}$ & COVID & Overall & $\begin{array}{c}\text { Pre- } \\
\text { COVID }\end{array}$ & COVID & Overall & $\begin{array}{l}\text { Pre- } \\
\text { COVID }\end{array}$ & COVID & Overall \\
\hline KSE & 36128 & 41631 & 38880 & -0.34 & -0.43 & -0.07 & 1.83 & 2.02 & 2.16 \\
\hline CPI & 10.11 & 8.59 & 9.35 & 0.41 & -0.46 & 0.93 & 1.99 & 6.10 & 3.59 \\
\hline IR & 12.4 & 7.37 & 9.89 & -0.62 & 2.46 & 0.25 & 1.64 & 7.65 & 1.33 \\
\hline BS & 5.08 & 4.61 & 4.84 & -0.02 & 0.26 & 0.68 & 1.36 & 3.23 & 2.48 \\
\hline IPI & 143.15 & 140.20 & 141.68 & 0.31 & -0.74 & -0.62 & 1.49 & 3.17 & 3.55 \\
\hline ExR & 148.67 & 160.45 & 154.56 & -0.29 & -0.20 & -0.78 & 1.26 & 2.72 & 2.52 \\
\hline MS & 17732 & 21231 & 19482 & -0.15 & -0.47 & -0.03 & 2.46 & 3.13 & 1.63 \\
\hline FDI & 192.27 & 158.20 & 175.23 & 1.85 & 0.39 & 2.07 & 6.09 & 5.05 & 8.80 \\
\hline
\end{tabular}

Table 1 reports descriptive statistics of the variables used in this study. Monthly observations of macroeconomic variables and the KSE index have been utilized from January 2019 to June 2021.

Table 1 shows the descriptive statistics of all variables used in the study in comparative form. It includes the mean and the measures of skewness \& kurtosis. The result shows that the values of skewness for all series are not significantly different from zero hence data series are not seriously departing from normality in preCOVID, COVID and overall scenario. Moreover, the kurtosis values shown in Table 1, indicate that most of the variables are platykurtic with lower than normal kurtosis in pre-COVID and overall period. However; most of the series are leptokurtic with higher than normal kurtosis in COVID situations. A leptokurtic return means that risks are coming from outlier events i.e. COVID situation.

\section{Unit Root Testing:}

This research study has employed the Augmented Dickey-Fuller Test (ADF) for the identification of stationarity and to avoid spurious regression of variables used in the study. 
Table 2: Augmented Dickey-Fuller tests (ADF) Test for Unit Root

\begin{tabular}{lcccccc}
\hline \multirow{2}{*}{ Variables } & \multicolumn{2}{c}{ Pre-COVID } & \multicolumn{2}{c}{ COVID } & \multicolumn{2}{c}{ Overall } \\
\cline { 2 - 6 } & T-Statistics & p-value & T-Statistic & p-value & T-Statistic & p-value \\
\hline KSE & -3.4345 & 0.0386 & -3.2524 & 0.0402 & -4.7724 & 0.0006 \\
CPI & -4.1062 & 0.0083 & -4.9366 & 0.0020 & -6.3311 & 0.0001 \\
IR & -5.4332 & 0.0008 & -3.6344 & 0.0401 & -2.7713 & 0.0749 \\
BS & -8.0861 & 0.0001 & -3.1359 & 0.0358 & -8.9157 & 0.0000 \\
IPI & -3.2879 & 0.0108 & -3.5239 & 0.0407 & -4.1046 & 0.0035 \\
ExR & -3.4386 & 0.0366 & -2.5782 & 0.0657 & -3.7797 & 0.0078 \\
MS & -4.6592 & 0.0032 & -4.9299 & 0.0023 & -6.0615 & 0.0003 \\
FDI & -3.1803 & 0.0328 & -5.1977 & 0.0015 & -7.7811 & 0.0001 \\
\hline
\end{tabular}

Table 2 describes the results of Augmented Dickey-Fuller (ADF). The test has been applied on all the variables both at the level and at first difference. The null hypothesis in the case of ADF state that data is having a unit root or is non-stationary. Overall, the results reveal that all the variables are stationary at their first difference, which implies that all are integrated at the same order one i.e. I (1). Hence, the null hypothesis of the unit root has been rejected.

\section{Cointegration Test:}

Johansen Cointegration Test has been applied to check the long-term equilibrium relation between nonstationary time series. The results of cointegration are given below:

Table 3: Results of Cointegration Tests

\begin{tabular}{llll}
\hline Variables & Pre-COVID & COVID & Overall \\
\hline CPI & $37.04(0.00)^{* *}$ & $16.18(0.04)^{* *}$ & $14.38(0.07)^{*}$ \\
IR & $21.13(0.01)^{* *}$ & $11.12(0.20)$ & $14.59(0.07)^{*}$ \\
BS & $27.69(0.01)^{* *}$ & $9.45(0.32)$ & $11.93(0.16)$ \\
IPI & $28.96(0.00)^{* *}$ & $16.48(0.04)^{* *}$ & $10.48(0.25)$ \\
ExR & $38.63(0.00)^{* *}$ & $16.17(0.04)^{* *}$ & $20.45(0.01)^{* *}$ \\
MS & $34.83(0.00)^{* *}$ & $12.36(0.14)$ & $6.34(0.65)$ \\
FDI & $22.79(0.01)^{* *}$ & $12.69(0.13)$ & $11.15(0.20)$ \\
\hline
\end{tabular}

Trace Statistics (Prob.), $5 \%$ Critical Value $15.49,{ }^{* *}\left({ }^{*}\right)$ denotes rejection of the null hypothesis at $5 \%$ and $10 \%$ significance level

Table 3 summarizes the results of the cointegration test of pre-COVID, COVID and overall periods. The Tstatistic determines the level of cointegration between the variables. From table 3 it is evident that there is co-integration between stock prices and all economic variables in the pre-COVID period as the trace values of all macroeconomic variables used in this study are greater than the critical value of 15.49. However, the pattern is different in the COVID period as there is a long-run relationship between KSE and CPI, IPI and ExR only. Likewise, the COVID has also affected the relationship in the overall period as KSE has the only relationship with CPI, IR and ExR. Thus, based on the results, there is evidence of cointegration as well as a long-run relationship between macroeconomic variables and stock prices of the KSE 100 Index. However, the pattern of relationship is different in the pre-COVID and COVID periods. 


\section{Granger-causality Tests:}

The results of the pairwise granger causality test are enumerated below:-

Table 4: Results of Pair Wise Granger-Causality Tests

\begin{tabular}{llll}
\hline Null Hypothesis & Pre-COVID & In-COVID & Overall \\
\hline CPI does not Granger Cause KSE & $2.45(0.09)^{*}$ & $0.08(0.92)$ & $0.71(0.50)$ \\
KSE does not Granger Cause CPI & $1.01(0.41)$ & $0.07(0.93)$ & $0.11(0.91)$ \\
IR does not Granger Cause KSE & $0.58(0.57)$ & $3.79(0.07)^{*}$ & $2.47(0.09)^{*}$ \\
KSE does not Granger Cause IR & $2.43(0.09)^{*}$ & $3.46(0.08)^{*}$ & $6.30(0.01)^{* *}$ \\
BS does not Granger Cause KSE & $4.29(0.04)^{* *}$ & $0.53(0.61)$ & $0.90(0.42)$ \\
KSE does not Granger Cause BS & $1.12(0.37)$ & $0.26(0.77)$ & $2.51(0.08)^{*}$ \\
IPI does not Granger Cause KSE & $0.82(0.47)$ & $3.84(0.07)^{*}$ & $10.89(0.00)^{* *}$ \\
KSE does not Granger Cause IPI & $0.82(0.48)$ & $1.79(0.23)$ & $1.99(0.16)$ \\
ExR does not Granger Cause KSE & $0.68(0.53)$ & $0.17(0.84)$ & $0.71(0.51)$ \\
KSE does not Granger Cause ExR & $0.84(0.47)$ & $0.92(0.44)$ & $0.03(0.97)$ \\
MS does not Granger Cause KSE & $0.22(0.81)$ & $2.86(0.09)^{*}$ & $0.35(0.71)$ \\
KSE does not Granger Cause MS & $0.01(0.99)$ & $1.38(0.31)$ & $0.36(0.71)$ \\
FDI does not Granger Cause KSE & $0.02(0.98)$ & $0.72(0.52)$ & $2.41(0.09)^{*}$ \\
KSE does not Granger Cause FDI & $3.71(0.07)^{*}$ & $0.61(0.57)$ & $0.22(0.81)$ \\
\hline
\end{tabular}

F-statistics (Prob.) ${ }^{* *}(*)$ denotes rejection of null hypothesis at 5\% (10\%) significance level.

Table 4 presents the results of the bivariate Granger causality test. The results show that stock returns do not have bidirectional causality with economic variables in the pre-COVID scenario. Whereas, CPI and BS have unidirectional causality with KSE and KSE uni-directionally granger cause IR and FDI. The same is supported by an earlier study on the impact of macroeconomic variables on the stock market in the United Kingdom, which also shows that inflation Granger causes the stock market Return of the UK (Neifar et al., 2021). CPI unidirectional causality with KSE is also supported by the Swedish stock market index OMXS30 study on macroeconomic variables, where inflation Granger causes the return of OMXS30 (Cengiz \& Holmer, 2021).In pre-COVID, change in the behavior of the Consumer price index and bank spread to produce a change in stock and stock market affect the interest rate and foreign direct investment.

During COVID, only bidirectional causality exists in KSE and IR. The result is in line with recent research on the impact of macroeconomic variables on the Swedish stock market index OMXS30, whose Granger Causality test showed a bidirectional relationship between interest rate and the return of OMXS30 (Cengiz \& Holmer, 2021). Whereas, IPI and MS unidirectional Granger cause KSE. The result of money supply unidirectional causality is in line with the results of an earlier study on the association between macroeconomic variables and the Lithuanian stock market, which also showed that money supply has a direct association with the stock prices(Pilinkus \& Boguslauskas, 2009). This implies that interest rate affects stock return and vice versa during COVID. Whereas, macroeconomic variables including MS and IPI produce a change in stock returns in the COVID scenario.

The results of the overall period also show bidirectional causality between KSE and IR. This shows that interest rate produces a change in the stock returns and stock returns also affect the interest rate. Whereas, IPI and FDI Granger cause KSE unidirectionally and KSE Granger cause BS. The overall result regarding IPI granger cause KSE is supported by earlier research regarding the linkage between macroeconomic factors and the stock market in Pakistan from 2011 to 2017 revealed that industrial production positively impacts the fluctuations of stock market returns (Aziz et al., 2021). The results also reveal that interest rate is used as an important tool of monetary policy, which has a significant short-run impact on stock returns during COVID.

\section{Impulse Responses Function}

The impulse response function posits that a shock to the i-th variable not only directly affects the i-th variable but is also sent to all of the other endogenous variables through the dynamic (lag) structure of the VAR. Moreover, an impulse response function also traces the effect of a one-time shock to one of the innovations on 
current as well as future values of the endogenous variables. Using a Choleski decomposition on a VAR model, we have calculated the following impulse response functions for the stock returns. The results of the impulse response function of each macroeconomic variable applied to three different data series are given below where the continuous line represents the estimated response function and the dotted line shows the confidence interval of the two standard deviations surrounding the estimate.

\section{Consumer Price Index Impulse Response Function}

A one standard deviation shock to the inflation rate decreases the stock returns in the Pre-COVID period. However, stock returns increase slightly during the COVID and there is a visible increase in the overall period against shock to the inflation rate. The effect remains significant for 2 months and then stock returns came back to their previous value after 3-4 months.

Pre-COVID

Response of RKSE to RCP

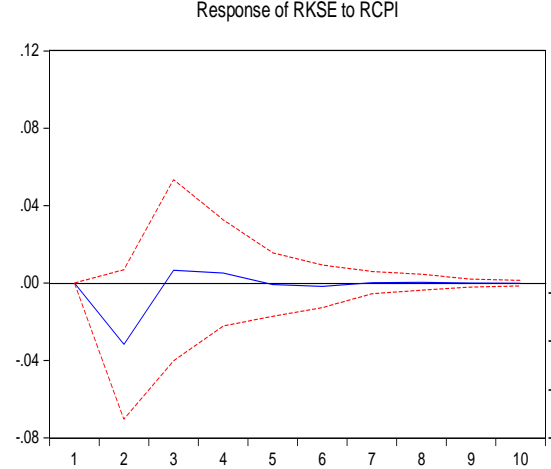

\section{COVID}

Response of RKSE to RCPI

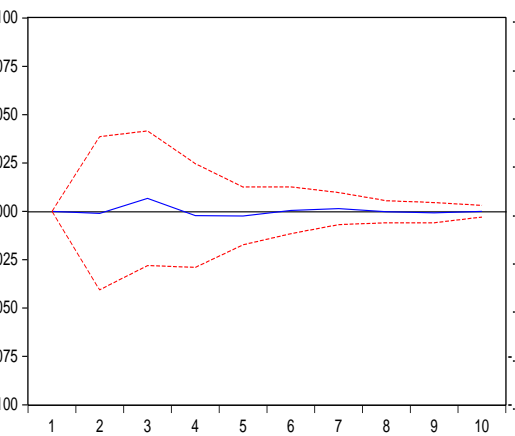

Overall

Response of RKSE to RCPI

Interest Rate Impulse Response Function

A one standard deviation shock to the interest rate decreases the stock returns in the Pre-COVID period and the effect dissipates after 5 months. However, it does not affect stock returns initially during the COVID period; the effect becomes significant after 4-5 months and stock returns decrease consistently. The pattern is completely different in the overall period where stock returns increase for 2 months against the shock and effect dissipates after 3 months.

Pre-COVID

Response of RKSE to RIR

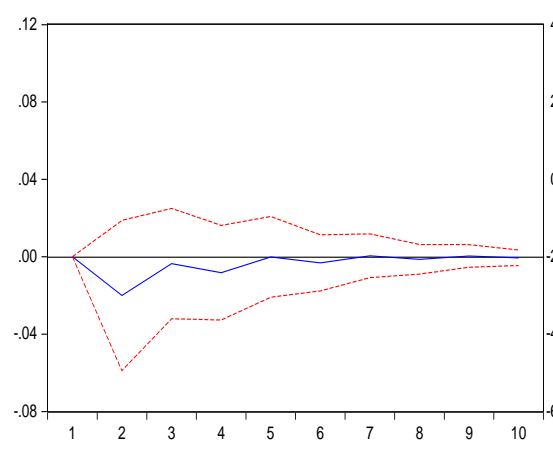

COVID

Response of RKSE to RIR
Overall

Response of RKSE to RIR

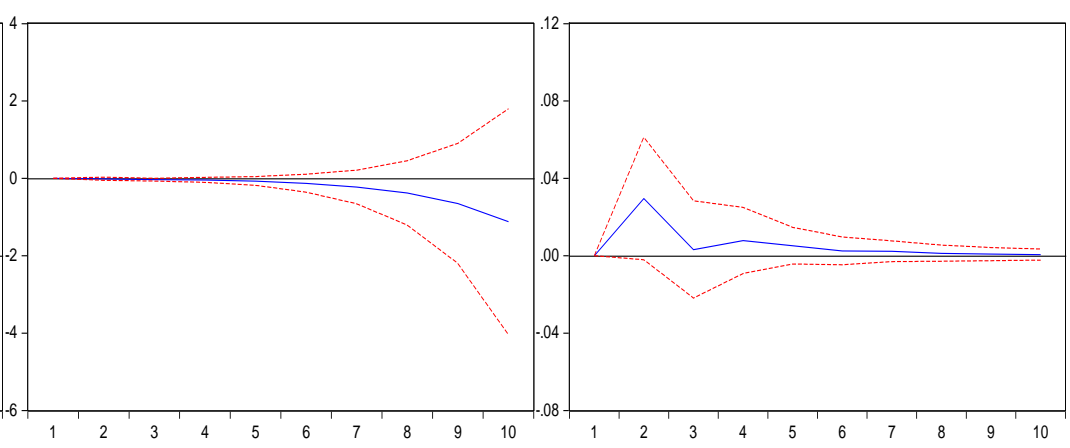

Bank Spread Impulse Response Function

A one standard deviation shock to the BS significantly decreases the stock returns initially for 2 months and then it attains its previous value after 5-6 months in the Pre-COVID period. It creates a continuous pattern of ups and down in stock returns during COVID. Whereas it increases the stock returns initially and then the effect dissipates after 4 months. 
Pre-COVID

Response of RKSE to RBS

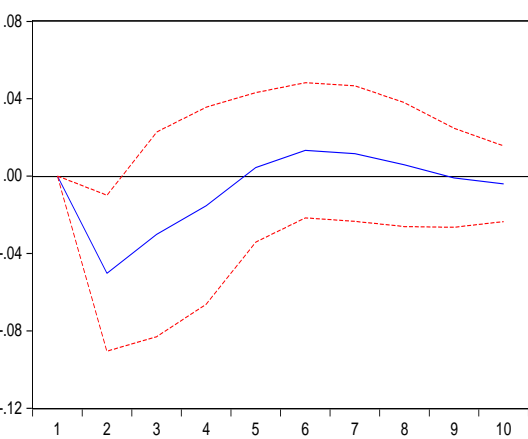

COVID

Response of RKSE to RBS

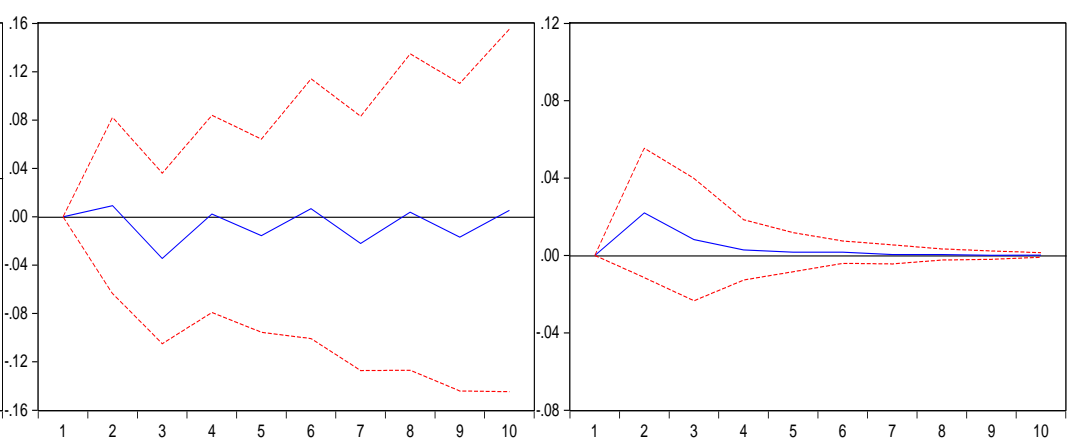

Industrial Production Index Impulse Response Function

A one standard deviation shock to the IPI increases the stock returns in the Pre-COVID and Overall period. The effect remains significant for 2 months and then stock returns decrease and become unresponsive after 4-5 months. However, it does not affect the stock returns initially during COVID. The effect becomes significant after 9 months and there is an upward trend in stock returns.

Pre-COVID

Response of RKSE to RIP

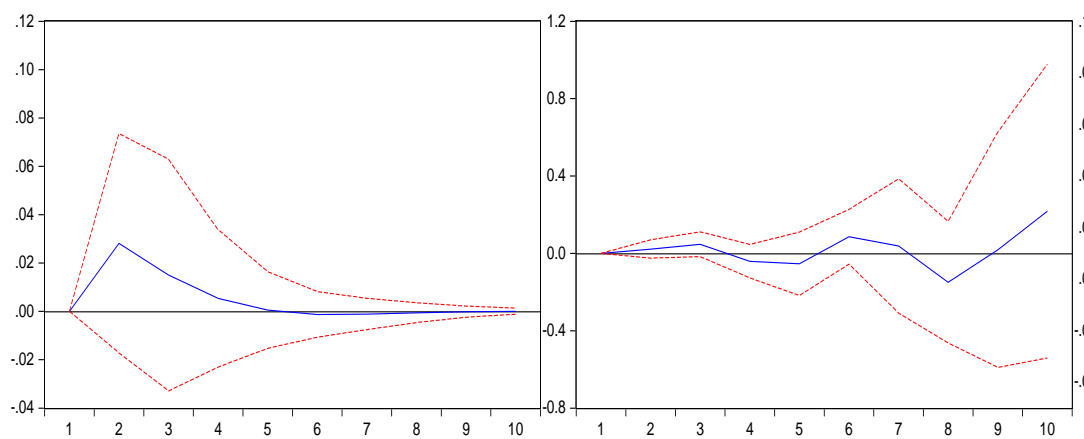

COVID

Response of RKSE to RIPI

\section{n}

Exchange Rate Impulse Response Function

A one standard deviation shock to the exchange rate decreases the stock returns for 2-3 months in Pre-COVID and the Overall period and effect dissipates after 4-5 months. However, during the COVID period, it slightly increases the stock returns for the first 2-3 months and then a slight decrease in stock returns and the effect dissipates after 5-6 months.
Pre-COVID

Response of RKSE to RER

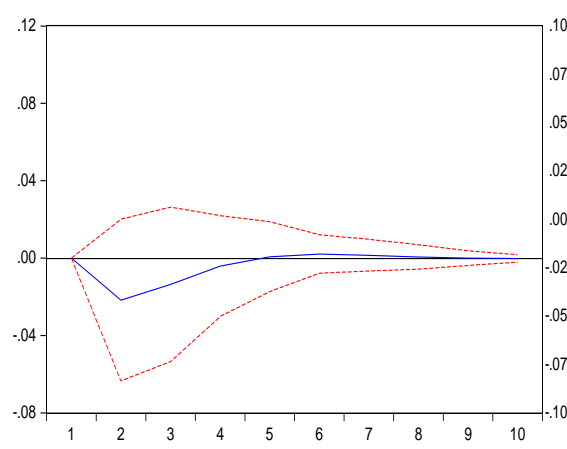

COVID

Response of RKSE to REXR

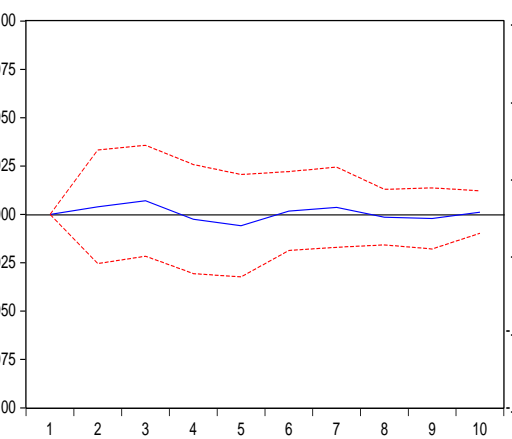

Overall

Response of RKSE to RIPI

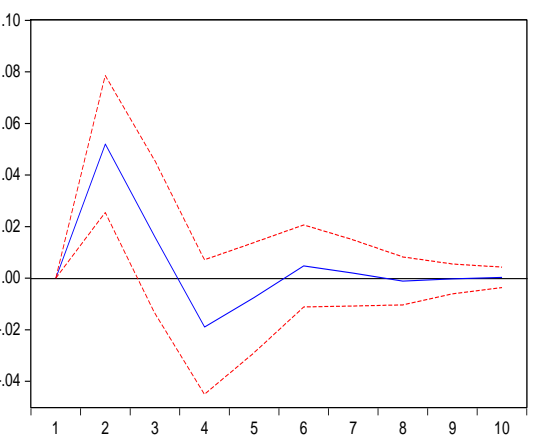

\section{Money Supply Impulse Responses Function}

A one standard deviation shock to the MS increases the stock returns initially for 2-3 months in both PreCOVID and Overall period, however, the impact dissipates after 4 months. However, initially, stock returns 
significantly increase for 2 months in the COVID period, and then it decreases for 2 next months and this pattern continues.

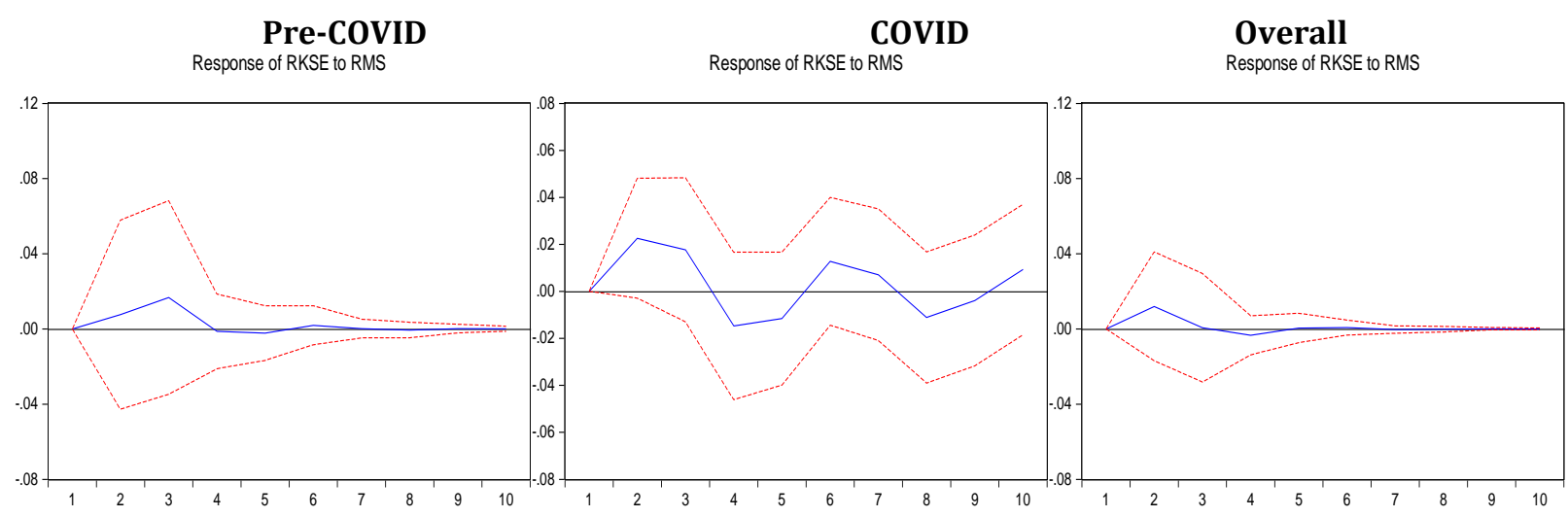

Foreign Direct Investment Impulse Response Function:

A one standard deviation shock to the FDI does not affect the stock returns in the Pre-COVID period. However, it slightly increases the stock returns for 2 months, then there is a decrease for the next couple of months and the effect dissipates after 7-8 months both during COVID and Overall period.

Pre-COVID

Response of RKSE to RFD

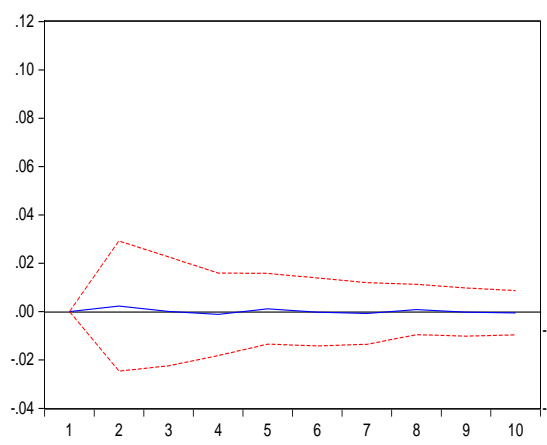

\section{COVID}

Response of RKSE to RFDI

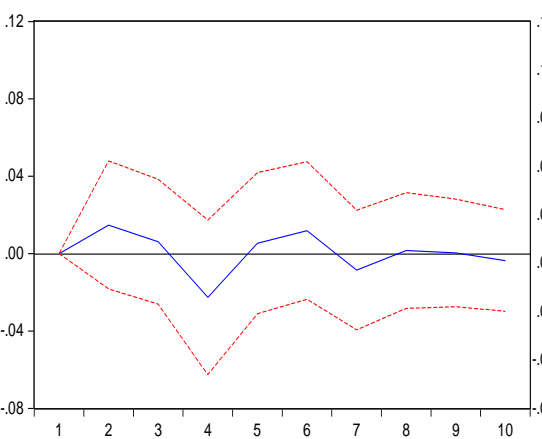

Overall

Response of RKSE to RFDI

The results of the impulse response function are not much different from the results of the other tests applied on 3 data series. It reveals that the relationship between economic variables and stock returns has been affected by the COVID pandemic and the response of stock returns to changes in economic variables during COVID is much different from the Pre-COVID period.

\section{Conclusion and Recommendations}

This study has been conducted to assess the impact of the dicey ongoing global COVID pandemic situation and association among macroeconomic variables and stock returns of the Karachi stock exchange of Pakistan. The results of the tests reveal that there is a long-term equilibrium relationship between all economic variables and stock prices in the pre-COVID period. However, most of the economic variables do not have such a relationship during the COVID period and the pattern of the relationship is almost the same in the overall period. It means that COVID has a certain effect on the relationship of economic variables with stock prices.

Correlation does not portray causation in any meaningful sense. The relationship is spurious or meaningless. Therefore, the Granger Causality test and Impulse Response Function have been applied to the pre-COVID, COVID and overall data sets. The results show that only some of the economic variables have a short-run relationship with stock returns in comparison to the cointegration test where all economic variables have a relationship with stock prices. In the pre-COVID period, changes in economic variables produced a change in stock returns in a predicted pattern supported by earlier studies on the subject. However, the reaction of 
stock returns is different against changes in macroeconomic variables like CPI, IR, IPI, MS and FDI during COVID. Therefore, the results revealed that economic variables affected stock returns differently in the COVID situation than in the Pre-COVID scenario and it also affects the short-run relationship in the overall period.

From the results, it is quite evident that the COVID pandemic has changed the set pattern of association between economic variables and stock returns both in the short-run and long run. Therefore both policymakers and investors should revisit their strategies regarding financial markets. The regulators should formulate both fiscal and monetary policies keeping in view the new dynamic relationships between economic variables and investors must look at the signals of the economic outlook in the emerging scenarios of the COVID regime. Keeping in view the implications of the findings of this study, investors and stakeholders need to weigh uncertainty associated with COVID-pandemic before making investment decisions. The tools of fiscal and monetary policy like interest rate, taxes and money supply must be handled by regulators differently during COVID. Since it may affect the investors' decision and availability of funds for the capital market. Further, this research study also provides ground for extending the impact of the COVID pandemic on money and bond markets, commodities as well as foreign exchange, which might also offer insightful findings for stakeholders.

\section{References}

Alam, M., \& Uddin, G. (2009). Relationship between interest rate and stock price: empirical evidence from developed and developing countries. International Journal of Business and Management (ISSN 18333850), 4(3), 43-51.

AMARKHIL, D. K., HUSSAIN, J., \& AYOUBI, M. (2021). Effect of Exchange Rate on Stock Return. JournalNX, 7(1), 297-310.

Aziz, T., Marwat, J., \& Mustafa, S. (2021). Macroeconomic Uncertainty and Stock Market Uncertainty: Some Further Evidence From Pakistan. Review of Pacific Basin Financial Markets and Policies, 2150014.

Baker, S. R., Bloom, N., Davis, S. J., \& Terry, S. J. (2020). COVID-induced economic uncertainty: National Bureau of Economic Research.

Bhuiyan, E. M., \& Chowdhury, M. (2020). Macroeconomic variables and stock market indices: Asymmetric dynamics in the US and Canada. The Quarterly Review of Economics and Finance, 77, 62-74.

Cengiz, T., \& Holmer, D. (2021). Macroeconomic variables and their impact on the Swedish stock market.

Chaengkham, S., \& Wianwiwat, S. (2021). The impacts of macroeconomic and financial indicators on the stock market index: evidence from Thailand. International Journal of Trade and Global Markets, 14(2), 197 205.

Dada, S. O. K., Mokuolu, F. T., Alabi, J. O., \& Miracle, K. (2021). Robust Application of the Arbitrage Pricing Theory and the Test for Volatility in the Stock Market: Evidence from Nigeria.

Engelhardt, N., Krause, M., Neukirchen, D., \& Posch, P. (2020). What drives stocks during the corona crash? News attention vs. rational expectation. Sustainability, 12(12), 5014.

Granger, C. W. J. (1986). Developments in the study of cointegrated economic variables. Paper presented at the Oxford Bulletin of economics and statistics.

Hillier, D., \& Loncan, T. (2019). Political uncertainty and stock returns: Evidence from the Brazilian political crisis. Pacific-Basin Finance Journal, 54, 1-12.

Ichev, R., \& Marinč, M. (2018). Stock prices and geographic proximity of information: Evidence from the Ebola outbreak. International Review of Financial Analysis, 56, 153-166.

Johansen, S. (1995). Likelihood-based inference in cointegrated vector autoregressive models: Oxford University Press on Demand.

Johansen, S., \& Juselius, K. (1994). Identification of the long-run and the short-run structure an application to the ISLM model. Journal of Econometrics, 63(1), 7-36.

Kartal, M. T., Ertuğrul, H. M., \& Ulussever, T. (2021). The Impacts of Foreign Portfolio Flows and Monetary Policy Responses on Stock Markets by Considering COVID-19 Pandemic: Evidence from Turkey. Borsa Istanbul Review.

Li, C., Su, C.-W., Altuntaş, M., \& Li, X. (2021). COVID-19 and stock market nexus: evidence from Shanghai Stock Exchange. Economic Research-Ekonomska Istraživanja, 1-14.

Markowitz, H. M. (1968). Portfolio selection: Yale university press. 
Neifar, M., Dhouib, S., Bouhamed, J., Ben Abdallah, F., Arous, I., Braiek, B., \& Mrabet, D. (2021). The impact of macroeconomic variables on the Stock market in the UK.

Peiro, A. (2016). Stock prices and macroeconomic factors: Some European evidence. International Review of Economics \& Finance, 41, 287-294.

Pilinkus, D., \& Boguslauskas, V. (2009). The short-run relationship between stock market prices and macroeconomic variables in Lithuania: an application of the impulse response function. Inžinerine ekonomika (5), 26-34.

Pole, H., \& Cavusoglu, B. (2021). The Effect of Macroeconomic Variables on Stock Return Volatility in the Nigerian Stock Exchange Market. Asian Journal of Economics, Finance and Management, 32-43.

Ross, S. (1976). The arbitrage theory of capital asset pricing, 'Journal of Economic Theory': Elsevier, Amsterdam.

Said, S. E,\& Dickey, D. A.(1984). Testing for unit roots in autoregressive-moving average models of unknown order+. Biometrika, 71, 599-607.

Sheikh, U. A., Asad, M., Israr, A., Tabash, M. I., \& Ahmed, Z. (2020). Symmetrical cointegrating relationship between money supply, interest rates, consumer price index, terroristic disruptions, and Karachi stock exchange: Does global financial crisis matter? Cogent Economics \& Finance, 8(1), 1838689.

Topcu, M., \& Gulal, O. S. (2020). The impact of COVID-19 on emerging stock markets. Finance Research Letters, 36, 101691.

Torbira, L. L., \& Agbam, A. S. (2017). Macroeconomic Risk Factors and Stock Returns: The arbitrage pricing approach. Journal of Finance, Banking and Investment, 4(1), 41-71.

Uddin, M., Chowdhury, A., Anderson, K., \& Chaudhuri, K. (2021). The effect of COVID-19 pandemic on global stock market volatility: Can economic strength help to manage the uncertainty? Journal of Business Research, 128, 31-44.

Younis, I., Longsheng, C., Basheer, M. F., \& Joyo, A. S. (2020). Stock market comovements among Asian emerging economies: A wavelet-based approach. PloS one, 15(10), e0240472. 